\title{
CAUSALIDADE E OPERAÇÕES EM PIAGET
}

\author{
Zélia Ramozzi-Chiarottino
}

Uma das dificuldades da obra de Jean Piaget, construída ao longo de mais de quarenta anos, tem sido a, pelo menos aparente, separação entre o conhecimento do mundo físico e as operações lógicomatemáticas .

Se considerarmos as razões do próprio Piaget veremos que a primeira condição para que esse problema seja resolvido é a de entendermos o papel que desempenha, dentro de sua teoria, "o poder construtivo interno (e não exógeno) da ação e das operações que a prolongam"

A hipótese de Piaget é a de que através das ações do sujeito, a partir dos esquemas motores, dá-se a troca do organismo com o meio graças a um processo de equilíbrio progressivo, protótipo de uma "construção dirigida" ao nível do ser humano, que é responsável pela construção das suas estruturas racionais (razão ou inteligência) Estas estruturas, cujo funcionamento ${ }^{1}$ é o mesmo de toda organização viva, caracterizam-se, de um lado, por serem um prolongamento das estruturas orgânicas (já conhecidas), e de outro lado por constituirem uma especialização (um órgão especializado) em relação a elas.

As estruturas racionais, ou mentais segundo a hipótese de Piaget, são responsáveis pelas estruturas operatórias que se encontram no comportamento do sujeito e também pelas suas operações abstratas. Por não terem sido observadas são explicadas através de dois modelos: os agrupamentos de classes e relações, correspondentes ao período lógico-concreto, quando a criança é capaz de usar uma lógica ainda vinculada à manipulação dos objetos e o grupo INRC, correspondente ao período lógico-abstrato, quando o ser humano torna-se capaz de empregar uma lógica independente da manipulação de objetos.

(1) - Esse funcionamento geral, diz Piaget, obedece a uma determinada lógica de classes e relações. 
Para Piaget o aspecto fundamental da ação é produzir. A previsão é necessária à própria ação produtora, mas o núcleo funcional da ação é modificar os objetos e os acontecimentos.

A ação destrói a dicotomia razão e real. A explicação da origem do conhecimento não está nem no objeto como tal, nem no sujeito como tal, mas num complexo indissociável de interações entre sujeito e objeto que é fornecido pela ação.

Há dois aspectos a serem considerados na ação da criança: $1^{\circ}$ ) a ação exercida sobre os objetos (como empurrar, puxar, levar e trazer) que são a fonte da causalidade, do conhecimento do mundo físico; $2^{\circ}$ ) a coordenação entre essas ações tais como a ordem (constatável na utilização de meios conduzindo a determinados fins ou em quaisquer ações articuladas) o encaixe (de um esquema no outro), a correspondência termo a termo, etc., que são fonte das futuras operações lógico-matemáticas. As relações estabelecidas na coordenação das ações serão representadas e posteriormente transformadas em operações das abstrações reflexivas.

A operação não é a representação de uma ação: ela ainda é, pode-se dizer, uma ação na medida em que constroi novidades, mas é uma ação "significante" e não mais física, pois que as ligações que ela utiliza são de natureza implicativa e não mais causal. A operação não é uma ação qualquer, ela é reversível, conserva seu objeto no decurso das transformações que são reversíveis. As operações não estão jamais isoladas, ao contrário, formam totalidades que obedecem a leis de composição interna.

Assim, a hipótese de Piaget é a de que tanto a causalidade quanto as operações lógico-matemáticas têm sua origem comum na ação.

No comportamento da criança há, inicialmente, uma indiferenciação entre as relações causais e as relações lógicas. Permanecendo indiferenciadas, elas se contrariam e é graças à contradição e ao desequilíbrio por ela causado que a criança chegará à diferenciação e à coordenação destas estruturas.

Piaget cita como exemplo típico dessa indiferenciação o da criança que, colocada diante de vinte contas de madeira, das quais 15 são pretas, e à qual se pergunta se o colar que se poderia fazer com as contas de madeira seria maior ou menor que aquele feito de contas pretas, respondeu, em substância, que o colar de contas pretas seria mais comprido porque estas uma vez enfiadas no cordão não poderiam ser retiradas para fazer outro colar: resposta irrefutável, diz ele, se se trata de ações causais sincronizadas, demonstrando o fato de que 
O aspecto causal da ação engloba suas dimensões espaço-temporais, suas velocidades e seu dinamismo, enquanto as ligações lógicomatemáticas fazem abstração dessas condições físicas para reter apenas a forma das coordenações, como já foi dito. A dificuldade está justamente em explicar como o pensamento do sujeito pode passar de uma situação onde quase tudo é sucessivo e causal a uma situação que permite estabelecer relações atemporais entre formas estáveis ou susceptíveis de serem reencontradas.

Segundo Piaget, há dois processos complementares que conduzem a este resultado e que parecem responsáveis pela diferenciação progressiva entre o lógico-matemático e o causal: de um lado a representação que torna possível os quadros que englobam simultaneamente os fatos passados presentes e futuros, que no plano das constatações perceptivas permanecem sucessivos; de outro lado a intervenção de auto-regulações, introduzindo nestes sistemas um equilíbrio móvel, de tal modo que as coordenações possam ser efetuadas nos dois sentidos, direto e inverso (ou recíproco) e se transformarem assim em operações reversíveis. A noção física do virtual diz respeito a possibilidades cujas compensações podem ser simultâneas mas cujas realizações são sucessivas, enquanto que todos os possíveis permanecem simultâneos para o pensamento apenas pelo fato de que eles são concebidos como possíveis: o que caracteriza o raciocínio hipotéticodedutivo é justamente passar diretamente do possível ao necessário pelo estabelecimento de relações entre os primeiros sem ser por intermédio do real. Aliás é esse o critério para se reconhecer a chegada da criança à etapa do pensamento formal. Esta oposição entre o possível e o real é que explica as múltiplas diferenças que subsistem entre as operações e as relações repetíveis do mundo físico.

"A causalidade exprime as transformações do real enquanto as operações traduzem aquelas de uma estrutura racional. Resta saber se o sujeito pode alcançar as primeiras sem ser por intermédio das segundas"

Explicar a causalidade independentemente das operações do sujeito, diz Piaget, significaria considerar as relações causais como dados diretamente observáveis na experiência imediata dos objetos ou das ações e como podendo daí serem retiradas por abstração simples (em oposição à abstração reflexiva ou lógica-matemática)

O problema seria justamente o de verificar se na relação causal há simples constatação ou se existe construção ou composição, à semelhança do que acontece nas operações.

Piaget considera que há dois dados fundamentais a serem considerados no que diz respeito ao conhecimento do mundo físico, e por- 
tanto às relações entre as operações do sujeito e a causalidade dos objetos: o primeiro é uma questão exaustivamente estudada pela escola piagetiana, ou seja que a leitura de uma experiência exige o emprego de instrumentos de assimilação do sujeito graças aos quais essa leitura é possível, em outras palavras, ela supõe as estruturas operatórias. Por exemplo, julgar que a quantidade de líquido se conserva num transvasamento implica já uma transitividade. A abstração "simples" ou física, que tira sua informação do objeto, supõe as ligações devidas ao sujeito: "esta pedra é branca", implica classificação. ${ }^{2} \mathrm{O}$ segundo dado essencial é o de que as conexões causais, dependendo em parte das informações obtidas por abstrações simples, ultrapassam inevitavelmente, enquanto conexões, o domínio dos observáveis. Nós observamos deslocamentos ou transformações qualitativas, mas estas são apenas as manifestações exteriores de uma relação causal que se trata de construir por inferência. Devendo ser deduzida, ela não pode sê-lo a não ser por intermédio de operações e a fonte dessas operações só pode ser encontrada nas "abstrações reflexivas" Esta abstração que se dá a partir das ações ou operações é construtiva, porque transpõe a um novo plano aquilo que é tirado do plano anterior, reconstruindo e recombinando neste novo plano o que estava dado no precedente.

As relações observáveis na natureza, enquanto isoláveis, são apenas leis, ainda que gerais. A relação causal necessária só existe quando um sistema de leis adquire o caráter de necessidade enquanto sistema. Para que haja necessidade é necessário então que haja sistema, logo dedução. Por exemplo, a criança descobre, bem antes de entender a razão disto, que dois pesos pendentes, presos em fios separados um do outro de 30 a $60^{\circ}$, tem uma resultante inferior à dos mesmos pesos se os fios forem encurtados; mas esta lei, cuja verdade é inicialmente constatada somente a título de simples fato geral, torna-se necessária quando inserida num sistema que coordena as intensidades e as direções e que implica a consequência de que duas forças iguais e opostas se anulam.

Mas de que tipo de dedução se trata aqui? Responde Piaget: se uma lei, cujo domínio é relativamente particular, é em seguida englobada numa lei mais geral, podemos certamente deduzir a primeira da segunda, mas esta dedução não acrescentará nenhuma necessidade à primeira a não ser sob uma forma hipotética: "se a segunda lei se verifica, então a primeira é necessária", trata-se de uma dedução silogística que não comporta nenhuma estrutura de composição a não ser pela transferência de verdade do geral ao particular.

(2) - Este tema tem sido amplamente discutido por Piaget nos Etudes d'épistemologie génétique, IV, V e VII. 
Ao contrário, diz Piaget, logo que a composição dedutiva deixa de ser simplesmente silogística e conduz a estruturas suceptíveis de se fecharem sobre elas mesmas, a necessidade que se prende ao fechamento da estrutura constitui então o princípio da explicação causal das leis assim agrupadas, porque este fechamento fornece condições necessárias e suficientes. Um dos exemplos que Piaget nos dá dessas estruturas explicativas é o do grupo de transformações no qual uma transformação permanece sempre interior ao sistema, porque resulta da composição de dois elementos ou transformações pertencentes já ao sistema e onde a composição é ao mesmo tempo reversível e associativa.

E preciso notar antes de tudo, diz Piaget, que a reversibilidade do grupo não se reduz à identidade, porque a operação inversa T-1 anula a operação direta $\mathrm{T}$ e não se confunde com ela, e porque a operação frequentemente chamada de idêntica ou elemento neutro 0 ou 1 (de maneira geral $E$ ) não é uma identidade isolável, mas um produto de composições. As composições são ao mesmo tempo produtoras de novidades ou de diversos e necessários, na medida em que o sistema é fechado sobre ele mesmo. Daí resulta, segundo o critério que Piaget propõe para a causalidade, que uma dedução apoiando-se sobre uma estrutura de grupo adquire o valor de explicação causal, pois ela permite entender a novidade ao mesmo tempo como produção e como necessária. Por exemplo, na explicação de por que uma força toma a direção $\mathrm{AD}$, a explicação é que esta força é a adição vetorial de duas outras de direções $\mathrm{AB}$ e $\mathrm{AC}$, a direção $\mathrm{AD}$ corresponde à diagonal do paralelogramo cujos lados são $\mathrm{AB}$ e $\mathrm{AC}$ : enquanto constatação geral a relação entre $\mathrm{AD}$ e $\mathrm{AB}+\mathrm{AC}$ é apenas legal, mas ela se torna causal se o paralelogramo das forças é deduzido apoiando-se sobre sua estrutura de grupo.

Ora, esta dedução não pode se dar a não ser graças às estruturas do sujeito. Já dissemos, a causalidade exprime as transformações do real, enquanto as operações traduzem as de uma estrutura racional; resta, no entanto, o fato de que para alcançar as primeiras o sujeito tem necessidade de fazê-lo por intermédio das segundas, pois como vimos a causalidade só pode ser entendida como uma construção operatória .

De um lado o sujeito pode apenas "aplicar" suas operações aos objetos dando origem às funções ou relações legais: neste caso, o conteúdo dessas aplicações é fornecido pelos objetos, mas já estruturados pelas medidas ou outras operações do sujeito. De outro lado, na relação causal, trata-se de operações atribuídas aos objetos e que consistem em transformações operatórias devidas às estruțuras do sujeito, mas colocadas em correspondência com as transformações cau- 
sais do real, não observáveis como tais mas somente deduzidas a partir dos observáveis.

Quanto à diferença entre aplicação e atribuição o critério é simples: quando o sujeito faz classificações, seriações ou medidas, é ele que age enquanto os objetos são apenas manipulados sem imporem ao sujeito uma operação em vez de outra. Quando, ao contrário, uma composição operatória é atribuída ao objeto como a transitividade no caso da transmissão de calor, são os objetos por assim dizer que agem; nesse caso, que asseguram a transmissão. E claro que o sujeito conserva sua atividade própria pois uma operação atribuída aos objetos é sempre ao mesmo tempo uma aplicação de suas estruturas ao real, mas a recíproca não é verdadeira: por exemplo, dez pedrinhas só são dez porque o sujeito as coloca em correspondência a outros conjuntos; ao contrário, um movimento se transmite sem a intervenção do sujeito. E claro, diz Piaget, que a criança crê que o número está nas pedras, como crê que uma montanha sempre teve seu nome, e, quando atribui a transitividade aos movimentos das bolinhas, não percebe que de fato está imaginando que estas operam da mesma forma que ela.

A atribuição de operações a um sistema físico considerado como causal pode não ser adequada. Frequentemente há contradições entre os fatos observados e o modelo operatório escolhido para explicá-los, e nesse caso o sujeito procura um novo sistema de operações atribuíveis aos objetos. Aqui também a superação das contradições pode implicar um jogo de influências que, pela sua natureza dedutiva, constituirá uma estrutura nova.

Finalmente, a hipótese de Piaget é a de que a causalidade se explica em termos de estruturas operatórias atribuídas aos objetos, o que significa de um lado que elas existem de uma forma ou de outra nos próprios objetos, mas de outro lado que só podem ser entendidas por intermédio das estruturas do sujeito. $O$ primeiro aspecto fornece as conservações e o segundo as transformações.

"En effet, malgré le rôle dévolu de cette manière aux opérations du sujet dans la constitution de la causalité, il n'y a pas là d'interprétation idéaliste puisque ces opérations se rattachent néanmoins au réel, mais par l'intermédiaire des actions et de l'organisme lui-même, et non pas sous la seule pression de l'expérience. Ce qui manque à cet égard à la doctrine de Meyerson, comme d'ailleurs à celle de Brunschvicg, est une épistémologie biologique qui relierait les structures physiques à celles des mathématiques. Mais comme ce lien demeure intérieur au sujet par la médiation de l'organisme, il n'est pas question non plus d'un simple matérialisme, puisque par leurs 
constructions continues les opérations atteignent l'intemporel et l'univers infini des possibles qui déborde de toutes parts le réel." 3

Este apelo a uma epistemologia biológica e ao organismo pode até ser chocante, mas se justifica se nos lembramos de que segundo o próprio Piaget a primeira condição para que se resolva o problema das relações entre a causalidade e as operações é, como citamos no início deste pequeno artigo, a de estendermos "o poder construtivo interno (e não exógeno) da ação e das operações que a prolongam."

Quase todos os comentadores de Piaget procuram não entender este aspecto fundamental de sua teoria: ou seja, o de que a troca do organismo com o meio determina a construção orgânica das estruturas mentais ou racionais. Daremos aqui apenas uma indicação do problema, que só se esclareceria realmente se apresentássemos o modelo criado por Piaget para explicar as relações entre genótipo e fenótipo.

Diz Piaget que, sem invocar a transmissão dos caracteres adquiridos no sentido lamarckista, ou os estudos recentes da ação do ARN sobre o ADN, procurou recentemente interpretar o fenômeno da fenocópia (phénocopie) observado por ele nas Limnaea stagnalis da seguinte maneira: se o meio engendra um fenótipo comum não há razão para que haja reconstrução endógena. Ao contrário, se a variação exógena é fonte de um desequilíbrio mais ou menos profundo, este pode afetar os gens reguladores correspondentes às regiões modificadas do organismo. Há uma repercussão do desequilíbrio assim criado, indicando por um feed-back a existência de uma perturbação nas sínteses comandadas pelo genoma.

Nesse caso o genoma "responde" através de uma produção de variações mais ou menos aleatórias e submetidas como todas as outras a mecanismos seletivos. Neste caso particular onde o fenótipo pertubou o equilíbrio do meio interno é este último que constituirá os instrumentos de seleção: haverá então "seleção orgânica" no sentido de Baldwin e é então normal que a. variação endógena termine por assemelhar-se ao fenótipo, pois ela foi obrigada por seleções a se moldar no quadro modificado pelo fenótipo. Os fenótipos estão na maioria dos casos ligados de perto ao comportamento, e no caso dos vegetais às variações chamadas reacionais. A passagem do exógeno ao endógeno parece assim constituir um processo geral e que ocorre em todos os domínios da vida.

(3) - Piaget, "La causalité selon E. Meyerson" In: Les théories de la causalité, p. 207 
No que diz respeito às funções cognitivas, a reconstrução endógena remonta ao genoma; quer dizer que as ações dos objetos ou dos fatos do meio afetam os processos endógenos em um certo nível do descobrimento, com repercussão possível sobre aqueles que lhe são imediatamente anteriores ou sobre aqueles que estão em construção, mas sem colocar em questão toda a construção anterior. Isto porque na construção das estruturas mentais não há programação inata.

Os casos de fenocópias cognitivas explicariam a construção das estruturas mentais enquanto há relação direta entre o sujeito e o meio físico. No entanto a certa altura do processo dialético, graças ao qual se dá esta construção, a troca do organismo com o meio já não se restringe aos objetos como tais mas envolve os conceitos. Aqui então a construção se dá através das abstrações reflexivas, já mencionadas anteriormente, onde a nova estrutura é uma reconstrução da precedente, ao mesmo tempo que se constitui numa ampliação desta, generalizando-a pela combinação com os elementos específicos do novo plano de reflexão. "De plus, cette abstraction réfléchissante ne 'remplace' pas l'abstraction empirique, mais l'encadre dès le début puis la dépasse infiniment (au sens propre du terme) et l'univers des possibles logico-mathématiques ne remplace pas le monde réel, mais l'y plonge pour mieux l'expliquer, le premier étant donc une source mais non pas un siège de phénocopies." 4

Quer se trate de fenocópias biológicas ou cognitivas ou de abstração reflexiva, diz Piaget, reecontramos o mesmo mecanismo: uma reequilibração por reconstrução endógena e em seguida um ultrapassamento graças a uma reorganização com combinações novas mas cujos elementos são retirados do sistema anterior.

O princípio fundamental da explicação causal é o de que os sistemas constituídos pelos fatos observáveis e as leis, registrados de forma exógena, são substituídos por sistemas inferenciais cuja estrutura é a das operações do sujeito e cuja elaboração é portanto endógena.

"Le terme d'endogène parait néanmoins légitime du fait que ces structures ne sont pas tirées des objets, mais relèvent d'une activité logico-mathématique interne née de la coordination des actions du sujet: ces structures s'ajoutent alors, en leur servant de cadre assimilateur, aux propriétés de l'objet, mais sans en être extraites. De plus, à partir d'un certain niveau qui caractérise la logique et les mathématiques dites précisément "pures", ces structures endogènes n'encadrent plus d'objets (sinon des "objets quelconques") et fonction-

(4) - Adaptation vitale et psychologie de l'intelligence - Paris, Hermann, 1974, p. 88 . 
nent déductivement de façon exclusivement formelle, ce qui confirme rétroactivement leur caractère endogène. ${ }^{5}$

Instituto de Psicologia, Universidade de São Paulo

\section{BIBLIOGRAFIA}

Apostel, Mays, Morf e Piaget - Les liaisons analytiques et synthétiques dans les comportements du sujet. Paris, P.U.F., 1957 (Études d'Épistemologie génétique, 4).

Jonckheere, Mandelbrot e Piaget - La lecture de l'expérience, Paris, P.U.F., 1957 (Êtudes d'Épistémologie génétique, 5).

Piaget, J. - La construction du réel chez l'enfant. Neuchatel, Delachaux \& Niestlé, 1950.

Piaget, J. - Les relations entre le sujet et l'objet dans la connaissance physique. In: Logique et connaissance scientifique. Paris, Gallimard, 1967 (Encyclopédie de la Pléiade).

Piaget, J. - Biologie et Connaissance. Paris, Gallimard, 1967.

Piaget, J. - Causalité et opérations. In: Les explications causales. Paris, P.U.F., 1971 (Études d'Épistémologie génétique, 26)

Piaget, J. - La causalité selon E. Meyerson. In: Les théories de la causalité. Paris, P.U.F., 1971 (Études d'Épistémologie génétique, 25).

Piaget, J. - Réussir et comprendre. Paris, P.U.F., 1974.

Piaget, J. - Adaptation vitale et phychologie de l'intelligence. Paris, Hermann, 1975.

Piaget, J - L'équilibration des structures cognitives. Paris, P.U.F., 1975.

(5) - Ibid., p. 74 . 